\title{
Research on Financing Model of the Chinese SMEs in Supply Chain Finance
}

\author{
Yangyang Hu, Fang Wang \\ Graduate Department, Beijing Wuzi University, Beijing, China \\ Email address: \\ HYY_2016@126.com (Yangyang Hu), littlefang2011@163.com (Fang Wang)
}

To cite this article:

Yangyang Hu, Fang Wang. Research on Financing Model of the Chinese SMEs in Supply Chain Finance. International Journal of Economics, Finance and Management Sciences. Vol. 4, No. 5, 2016, pp. 235-240. doi: 10.11648/j.ijefm.20160405.11

Received: July 19, 2016; Accepted: July 29, 2016; Published: August 15, 2016

\begin{abstract}
In recent years, with the quickly development of the supply chain finance, the cost of corporate finance would become an important way for enterprises to solve their financial problems. In China, the financing model of supply chain finance mainly for accounts receivable financing, inventory financing pledge financing, advances and financing. Three financing models are used in different larger companies in common. But due to the presence of their own problems, financial supply chain financing model has not been effective used in the small and medium enterprises (SMEs). This paper first describes the major financing model of supply chain finance. Moreover, some problems existing in the supply chain financing in the process of SMEs will be exposed. Finally, aiming at the problems and putting forward the method to solve the problem and to inventory pledge mode as an example, the paper puts forward an optimized scheme.
\end{abstract}

Keywords: Supply Chain Finance, SMEs, Financing Model

\section{Introduction}

SMEs present strengths and weakness in general that include management which is not standardized, low credit, opaque financial information, as well as poor cash flow in a weak position in the supply chain and other issues [1]. From the financing point of view, SMEs are small and far less than the issuance of shares and bonds financing requirements. At the same time, due to the lower credit rating, financial accounting irregularities, lacking of collateral against the bank or not conforming standard collateral required, so it is difficult for SMEs to finance to a larger amount of money in financial institutions. In the private lending market funds, because of high lending rates and the short loan time, there is a serious repayment burden for SMEs. Therefore, most SMEs are facing financing problems.

Today, with the increasingly fierce competition and the growing of large-scale socialized production, the competition between enterprises is no longer the competition among enterprises, but between the supply chain and the supply chain. In each of the supply chain, there is a core enterprise and the majority of SMEs, which is the so-called "1+N" model [2]. This model has created the SMEs to survive in the edge of the supply chain. Because of the weak status of SMEs, the core enterprise will be deferred payment, or require its advance payment, which exacerbated the funding needs of SMEs to a certain extent. So, if SMEs can successfully take advantage of supply chain finance to finance and revitalize the capital, it is crucial to their survival and development.

\section{Financing Models of Supply Chain Finance}

\subsection{Accounts Receivable Financing}

In the " $1+\mathrm{N}$ " supply chain model, "1" refers to the core enterprise in the supply chain at the core of the supply chain; and "N" refers to the supply chain of small and medium enterprises in the supply chain marginalized. In the mode of supply chain financing of accounts receivable, "N" mainly refers to those at the upstream suppliers, namely corporate debt;" 1 " is the demand side of goods, namely corporate debt. These core enterprises often take advantage of their dominant position in the supply chain, requiring a deferred payment, which gives SMEs some financial pressure. Limited access to capital for SMEs can be mortgaged to the bank accounts receivable, thereby financing. The specific flow chart is shown in Figure 1. 


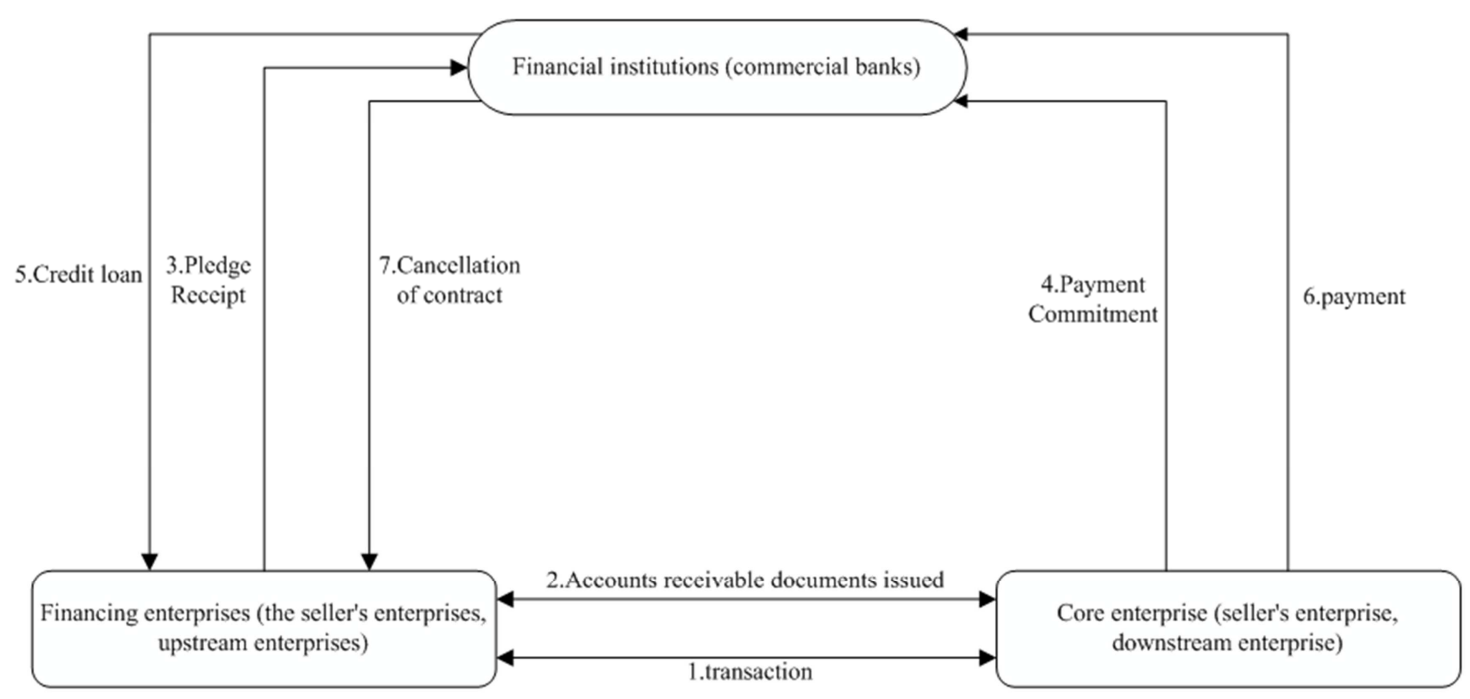

Figure 1. Accounts receivable financing model.

Accounts receivable financing should cope with the "loans difficult" situation in the small and medium-sized enterprise caused by real estate mortgage problems. The SMEs should be accounts receivable "invigorated, ease the pressure on the short-term liquidity and guarantee the production sustainable, as well as the entire supply chain normal operation [3].

\subsection{Inventory Pledge Financing}

Inventory pledge financing is generally suitable for SMEs in the supply chain, that is, vendors. The vendors need to advance purchase large quantities of goods to maintain a certain amount of inventory. This not only causes storage costs, but will also cause funds occupied, which easily lead to difficulties in the SMEs capital turnover. So in the Inventory pledge financing model, the SMEs just the stock pledge to the bank, and deliver to the bank designated by the third party logistics enterprises. The third party logistics enterprises confront collateral value assessment, custody and supervision [4]. According to the information feedback of the third party logistics enterprises, banks decided whether lend loan to SMEs. In the mode of inventory pledge financing, financing warehouse financing model is the most classic. Financing warehouse financing model specific flow chart figure 2 .

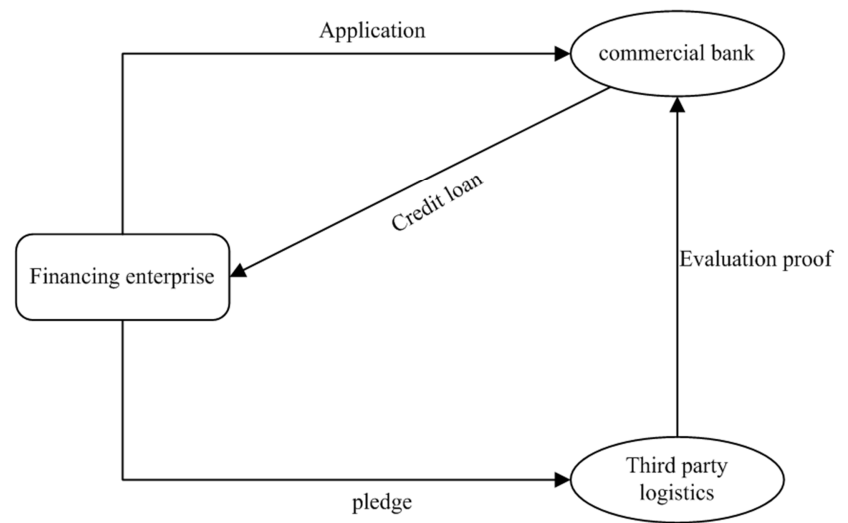

Figure 2. Financing warehouse financing model.
Inventory financing model is a kind of financing mode which is more popular among enterprises. SMEs in the lower reaches of the supply chain often need to advance purchase large quantities of goods, which makes originally "home base" thin. SMEs are facing greater financial pressure. But for inventory impawn financing mode, it makes a lot of inventory transform to the flow of funds flow. The revitalize the stock financing model, with the characteristics of financing cost low, is a high efficiency financing mode.

\subsection{Prepayments Financing}

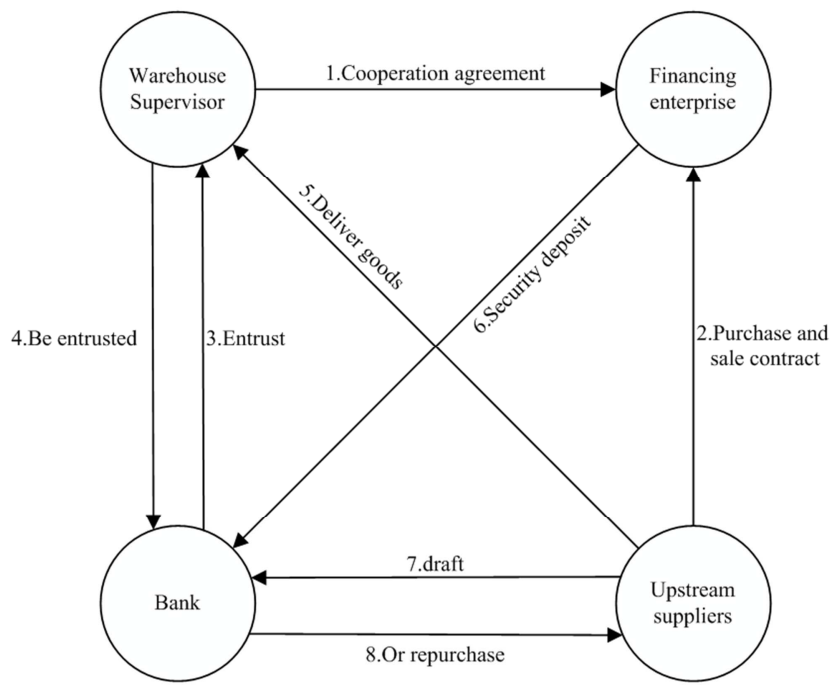

Figure 3. Prepayment financing model.

SMEs in the supply chain, in order to obtain the production of raw materials or semi-finished products, often need to advance to the core business to pay the advance payment. Advance payments will cause more difficulties to SMEs, and even lead to the fracture of the financial chain and the risk of survival. In prepayments financing mode, confirmation is a more typical warehouse financing model. In confirming warehouse model, SMEs pay a deposit to the bank, and then 
the bank issue bankers' acceptances, which ease the pressure of cash-strapped on SMEs in the short term. And the cost of this financing model is relatively lower which is favored by SMEs. Specific processes confirming positions are shown in Figure 3.

Prepayment Financing solves "financing difficulty" issued for SMEs, which need prepayments, and enable SMEs to get ahead of raw materials or finished products. Prepayment Financing enhances the anti-risk ability of SMEs. So it is a more universally applicable financing model [5].

\section{Problems in the Process of Using the Above Three Financing Modes}

In theory, those three modes as three kinds of successful financing model, not only can solve the problem of "financing difficult", but also can bring more substantial profit for banks, third-party logistics enterprises. Therefore, those three financing models will be strongly welcomed among SMEs, banks, third-party logistics companies. However, in reality, the situation is not the case, the three financing models are applied by more limits and application of the financing model is very difficult [6]. So, those three modes of financing do not bring much convenience to SMEs. The reason is summarized as follows.

(1) The low credit level SMEs, the small loan amount and the high cost of the audit. Due to the low level of credit and small amount of loans, in the audit process, the process is more complex, and the banks have a relatively high audit cost flat [7]. Because large enterprises have higher levels of credit, the amount of loans and banks in the process of audit of large-scale enterprise credit, business process has become relatively simple and apportion the audit cost is relatively low. Contrast to this area, so most banks follow more large enterprises, and are unwilling to accept the financing needs of SMEs, which makes SMEs get few benefits in the three modes.

(2) Preference of bank's lending is still stuck in the traditional credit business, and they are involved in new supply chain finance less. Due to short time of the rise of supply chain finance in China, the bank's main business is still a traditional business-oriented and less manpower, material and financial resources are put into supply chain finance. What's worse, the professional talents are few. All those objectively determine the banks are less involved in the supply chain finance, and even stay at a shallow level, or as a means to stay in the financing of large enterprises credit level. It means that banks have not carried out supply chain finance business in some depth SME level.

(3) The financial management of SMEs is not standardized and the financial information is not transparent. Because the strength of SMEs is weaker, and the internal mechanism is not perfect and standardized, especially the performance of financial management.
Because the internal mechanism of SMEs is not perfect, accounting and financial management standards is inconsistent with bank credit standards. Financial information is often not transparent enough. Asymmetric information between the banks and SMEs [8] leads to the banks facing all kinds of risks when they do credit business for SMEs. Those also make it unwilling to provide financing services for SMEs to avoid risks.

(4) The pledge of the SMEs is difficult to meet the requirements of the bank credit. Due to the small size of SMEs, the fixed asset that can be pledged are often less. And in the real practice, because of the default risk of accounts receivable, stock price volatility, short product life cycle and update replacement fast, the banks are reluctant to accept the SMEs' liquid assets as collateral [9]. At the same time, SMEs are difficult to find a suitable guarantee for its security. In terms of collateral security, the banks have a more stringent standard. SMEs' guarantees are difficult to meet the requirements of the bank. Therefore, the funds the SMEs get by using the fixed assets and liquid assets to finance are very limited.

(5) Activity information transparency of the SMEs in the supply chain is low. In the "Internet plus" era, Internet information technology has penetrated into various fields, which greatly improve the transparency of information from all walks of life. But due to the SMEs to their limited size, all kinds of inner mechanisms are not perfect. In order to reduce the cost, the new technology can't be used effectively. Even in terms of the implementation of the Internet information technology, the SMEs are far behind in the large-scale enterprises [11]. The application of Internet information technology is not in place, so that SMEs have the lower the transparency of activities in the supply chain process. If SMEs want to finance through the mode of financing warehousing, the bank or third party logistics enterprises can't monitor the status of the information in real time, which makes the credit side face greater risk. Therefore, banks refuse to SME financing request from a security point of view.

(6) It is difficult to bring the capital requirements and capital supply together for lacking of professional financing platform. As is known to all, the information of financing between demand side of the capital (SMEs) and funds (banks, the third party logistics enterprises, etc.) is often asymmetric, which makes the demand and supply of funds is difficult to achieve effective docking. In this case, there is an urgent need to the integrate resources and dock platform for information on both sides of the financing for the matchmaking. With such a professional financing platform, SMEs can be on the platform to show their financing intentions, and the financial supply side can decide whether to lend money according to its situation.

(7) Lacking of awareness of hedge funds, supply and 
demand sides are both faced with a huge risk. In other countries, whether large enterprises or small and medium enterprises, they all have a strong risk aversion, especially those who have survived hundred years which is to hedge as the top priority of the work. While domestic enterprises, risk aversion is not strong enough, especially SMEs. The SMEs are not only lack of awareness of risk, and even lack of effective hedging capability so that even if they take hedging measures, they can't achieve an effective hedging purpose. Therefore, such "family property thin children" has a poor anti-risk ability. And due to the lack of awareness of risk, the SMEs are faced with a lot of unnecessary risks. And after the bank credit, the SMEs don't take appropriate steps to avoid the risk of collateral in the face of the pledge. Even with pledge as collateral, the banks are also facing a huge risk of price changes pledge to bring [12]. As a result of the lack of risk aversion and ineffective hedges, those result in both the supply and demand of funds faced with a huge exposure. In this case, once the domestic macroeconomic situation deteriorated, many SMEs will face the collapse of the crisis. This has greatly increased the bank's bad debts, which is also an important reason for the reluctance of banks to lend money to SMEs.

\section{Solutions to the Problems}

Although SMEs are faced with various problems in the process of supply chain finance, the problem can be solved. We can target some of the problems, and put forward the corresponding solutions.

(1) In view of the problems of the SMEs' low credit level and the SMEs as a node in the supply chain. As a "N" in the " $1+\mathrm{N}$ " model, the SMEs can request a " 1 " that is the core enterprise to provide credit guarantee to improve the level of credit. In view of the small amount of loans and the problem of high cost of audit, banks should join hands together and even joint third party logistics enterprises to set up the supply chain finance credit rating agencies. The agencies play a role in diluted the role of audit cost, and not each bank independently establishes an evaluation department by investing more manpower, material and financial resources. Jointly building credit rating agencies aims to improve their expertise in credit assessment, effectively improve the reliability and safety of the audit, and greatly reduce the cost of the bank's business.

(2) Due to the increasing competition in the traditional areas, the market share is almost exhausted, which requires banks to maintain the traditional business and actively expand the development of new areas at the same time. And supply chain finance just rise in China, so the market is also very broad. There is a profit source can't be ignored by the banks. So, the majority of banks should be actively involved in the field to create more profits by making the supply chain finance related business bigger, deeper and professional.

(3) The SMEs should also standardize their own internal management structure, especially the financial management. Using standard accounting methods aims to guarantee the standardization of its financial management. At the same time, SMEs who have the financing needs should actively cater to banks on financial audit requirements to realize the joint of the financial management of SMEs and bank audit standards. The SMEs should improve the transparency of finance to facilitate the banks' audit before financing and banks' regulation after financing.

(4) In order to facilitate real-time monitoring after the banks lend money to SMEs, SMEs can use networking technology [12] to achieve SMEs' the operating system and the banks' system docking. This aims to achieve dynamic monitoring of bank liquidity SME goods or to achieve real-time monitoring of the SMEs' goods by a professional third-party logistics organization. Improving the transparency of the activities of SMEs can be more effective in reducing the risks faced by banks.

(5) In order to reduce the risk and dilute audit costs, the banks should jointly large-scale logistics enterprises, import enterprises and export enterprises to set up a special association spontaneously for the enterprise supply chain financing services (which may be called Supply Chain Financing Association). Supply Chain Financing Platform should be built by the association online and Credit Assessment Team should be formed at the same time. The SMEs who need money will issue financing request on the supply chain financing platform and indicate the demand for funds and collateral. The platform issues a request to the Credit Assessment team. The team scores the SMEs' condition according to its own credit rating system of an assessment and then feedback to the platform. The platform releases the enterprises credit rating status. Then the funds supplier decides whether to provide financing.

(6) The reason why Chinese banks are not willing to provide financing for SMEs is that banks don't want to take a huge risk, so avoiding risk is the key to solve the problem [13]. Under the background of today's financial tool innovation, SMEs and banks both need master effective hedging instruments, especially some derivatives, such as futures, options, forward rate agreements. Those hedging instruments can lock risk effectively, and then transfer or avoid unnecessary risks. At the same time, the banks should actively cooperate with the insurance companies to develop more appropriate, fit, effective insurance products, which plays the role of "double insurance" [14]. 


\section{Financing Model Optimization Scheme Based on Inventory Pledge}

Inventory pledge financing mode, namely money demand (SMEs) pledge their own inventory or warehouse elemental to capital supply side (commercial banks, the third party logistics enterprises, professional investment institutions) to obtain the cash flow of a financing model. Because of the information asymmetry between money demand and money supply side, the two sides are difficult to obtain cooperation. At the same time, original inventory pledge financing mode isn't taken effective measures to avoid risk, which has a greater risk exposure in the financing activities.

The optimized inventory financing mode has increased Supply Chain Financing Association, Supply Chain Financing Online Platform, Credit Assessment Team, insurance agencies and so on.

Supply Chain Financing Association is established by the commercial banks, import enterprises, export enterprises, and third-party professional logistics enterprises. The association is a self-regulatory organization to serve the supply chain financing the project. It solves the information asymmetry problem between the money demand and supply by building

the supply chain financing platform online. Through the integration of resources, it makes a match between money demand and supply.

Credit Assessment Team is a professional credit assessment team which is created by Supply Chain Finance Association by taking their own professional advantage. Credit Assessment Team creates a set which is a scoring rating system aiming to the demand side of funds the credit rating quickly, accurately and efficiently. At the same time, since the credit rating serve all the members on the supply chain finance platform rather than just a single commercial bank or investment institutions. Therefore, this avoids commercial banks spending a lot of manpower, material and financial resources to establish their own evaluation department and reducing the audit cost.

Meanwhile, optimized financing model cites derivatives futures, options, forward rate agreements, as well as insurance policies for collateral, which have the purpose of avoiding unnecessary risks. Doing this not only aims to reduce risk for the money supply side, but also improve the level of credit pledge which helps the money supply side pledge the warehouse receipt and reverse repurchasing in the face of tight cash flow situation.

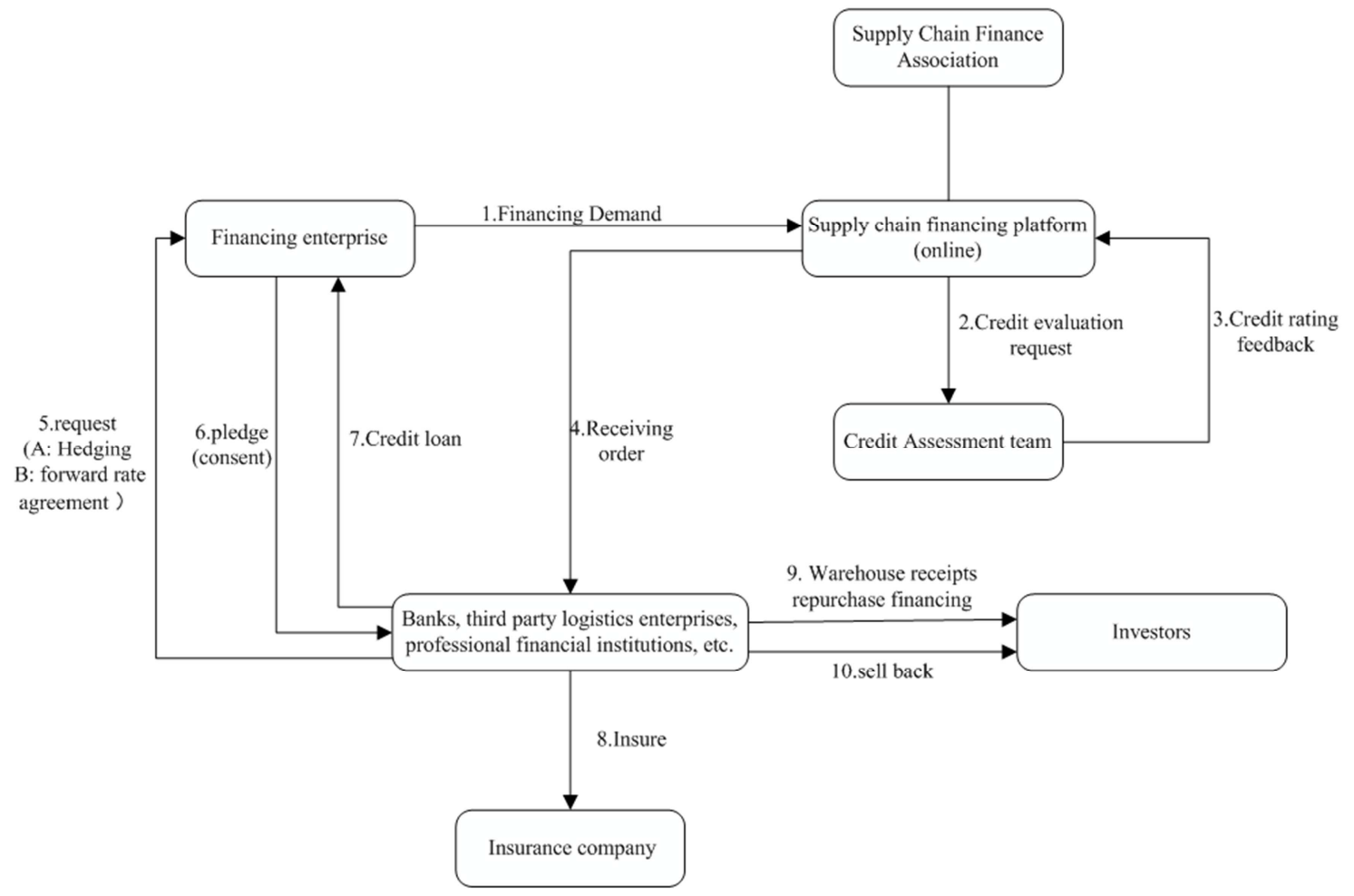

Figure 4. Inventory pledge financing model of the specific flow chart.

The process of optimizing the financing model of the deposit pledge is as follows:

(1) Financing enterprises that is funds the demand side indicate their intention of financing according to their financing needs on the supply chain financing platform, including the amount of financing, financing terms, financing affordable interval of interest rate, as well as collateral types.
(2) Supply Chain Financing Platform will submit financial information of the money demand side to the Credit Assessment Team who has the ability to score and rate by the credit of funds demand side

(3) When the Credit Assessment Team completes scoring and rating, the results will be fed back to the supply chain financing platform.

(4) The Supply Chain Financing Platform should put 
score rating results in the column of financing intentions of the money demand side so that the money supply side can clearly see the capital demand side of the credit rating. At the same time, according to the principle of the price (loan interest rate level) priority and time first, the Supply Chain Financing Platform formulate the appropriate funds providers (commercial banks, the third party logistics enterprises, professional investment institutions, etc.).

(5) The money supply side (commercial banks, third party logistics enterprises, professional investment institutions, etc.) request money demand side to hedge risk. This includes money demand side elect the appropriate derivatives (futures, options, forward rate agreements) to evade the risk of collateral faced according to the specific conditions.

(6) The money demand side agrees to use derivatives to hedge risk of pledge and then send the vouchers and receipts to the money supply side.

(7) After auditing the vouchers and receipts, the money supply side issues loans to the money demand side.

(8) According to the characteristics of pledges, the money demand side purchases insurance from the insurance company.

(9) The money supply side sells the warehouse receipt financing, and make an agreement on the time and price. The money supply side repurchases the warehouse receipt from investors one day in the future.

(10) When reverse repurchase expires, the money supply side repurchases warehouse receipt according to the agreed price.

The following Figure 4 is optimized inventory pledge financing mode specific flow chart:

\section{Conclusion}

The development of supply chain finance rapidly provides an effective financing model for SMEs. However, there are still some problems in the process when SMEs take the use of supply chain financing. There are two main reasons --- risks and costs. Therefore, only taking control of the risk in the supply chain finance financing, reducing audit costs and regulatory costs can promote the money supply participate in the supply chain financing efficiently and effectively. Improving the breadth and depth of their participation can resolve the problem of financing SMEs and bring real "gospel" to the SMEs.

\section{References}

[1] Wang Dan, Wu Zhengxiong. Research on supply chain financing of SMEs [J]. Northern Economy, 2013, 17: 61-62.

[2] Jiang Boqing. Discussion on the risk prevention measures of receivables financing mode based on Supply Chain [J]. Times Finance, 2015, 35: 285-291.

[3] XU Liang. Research on the Application of the Internet of Things Finance to Bulk Commodity E-trading Market [J]. China Business And Market, 2016, 01: 64-69.

[4] Man Shuwang. The Research on Supply chain Finance Based on Financing SMEs [J]. Marketing Management Review, 2016, 01: 86-87.

[5] Lian Ziying. Research on Supply chain Finance Based on Financing SMEs [J]. New Economy, 2016, 02: 57.

[6] Cheng Zhiliang. A preliminary study on the financing plan of prepayment financing from supply chain management perspective [J]. Market Modernization, 2015, 29: 116-117.

[7] Du Yamin. Research on supply chain risk assessment and solutions [J]. Modern Economic Information, 2016, 01: 78-79.

[8] Wu Chunping. Analyses of Financial Risk Early Warning and Prevention and Control of Supply Chain [J]. Logistics Enginerring and Management, 2016, 01: 54-56+44.

[9] Feng Xiaowei, Wang Chengfu, Xi Lei. The risk identification and control of supply chain financing under the financial model of the Internet of things [J]. Journal of Commercial Economics, 2016, 03: 180-182.

[10] Yu Junlin, Yuan Juan. Brief Analysis of Supply Chain Financing Mode of SMEs [J]. Science Mosaic, 2014, 11: 231-237.

[11] Zhang Xiaoying, Zhang Feng, Liu Kai. Analysis on the problems and improvement strategies of supply chain finance in China [J]. Modern Economic Information, 2014, 22: 353.

[12] Chang Wenguang, Niu Pengying, Zhang Yun. Study on the Information Risk of Supply Chain Finance Based on the Perspective of Commercial Banks [J]. Value Engineering, 2014, 30: 34-36.

[13] Xin Yuhong, Wei Yue. Research on the revenue sharing contract of inventory pledge financing in Supply Chain Finance [J]. Hainan Finance, 2014, 12: 10-13+22.

[14] Xie Haiyao. A Reference Research on the Application of Financial Derivatives in China's Commercial Banks [D]. China Agricultural University, 2014. 